Original study.

\title{
Histologic changes in eccrine apparatus in patients with Sjogren syndrome and no evidence of anhidrosis.
}

\author{
Tatsiana Pukhalskaya ${ }^{\text {* }}$, Bruce R. Smoller ${ }^{1}$ \\ 1 University of Rochester Medical Center (URMC); bruce_smoller@urmc.rochester.edu \\ * Correspondence: tatsiana_pukhalskaya@urmc.rochester.edu; Tel.: +1(585)7478684
}

Citation: Lastname, F.; Lastname, F.; Lastname, F. Title. Dermatopathology 2021, 8, Firstpage-Lastpage. https://doi.org/10.3390/xxxxx

\begin{abstract}
Sjogren syndrome (SS) is an autoimmune disease that involves salivary and lacrimal glands. There are rare articles describing hypohidrosis or anhidrosis in SS patients. Little is known about the histologic findings seen in patients with SS who do not report decreased sweating. We analyzed skin samples from 31 patients with SS who had undergone skin biopsies for reasons not related to SS. We assessed the number, distribution and pathologic changes within and around the eccrine ducts, glands and acrosyringia. The composition of the inflammatory infiltrate was additionally accessed utilizing immunohistochemical stains. Overall, in $60 \%$ of cases we observed some degree of inflammation. In virtually all cases the inflammatory infiltrate was located around the eccrine ducts at a distance from the non-SS pathology. It was mainly composed of CD3+ T cells with increasing number of B and plasma cells as periductal inflammation intensified. This study is the first histologic analysis of asymptomatic skin in patients with SS. It demonstrates the presence of skin involvement in the majority of SS patients. Our results emphasize the importance of systematic skin evaluation in this category of patients as well as counseling, early preventive measurements and timely treatment when indicated.
\end{abstract}

Sjogren syndrome; xerosis; anhidrosis; eccrine apparatus

\section{Introduction}

Sjogren's syndrome (SS) is an autoimmune disease with a broad range of clinical manifestations. It was first described in 1930 by a Swedish ophthalmologist, Henrik Sjogren, as a case of keratoconjunctivitis sicca associated with rheumatoid arthritis [1]. This syndrome can present as a primary disease or as secondary SS by accompanying other autoimmune conditions. It is more frequent in women, peaking around 50 years old [2].

Central to the pathogenesis of SS is the production of autoreactive B and T cells, antiRo/SSA and anti-La/SSB autoantibodies, formation of ectopic lymphoid aggregates and hypergammaglobulinemia [3]. Disease-associated autoantibodies can be found several years before the diagnosis is established and first symptoms manifest.

The exact cause of SS is not definite and most probably multifactorial. Genetic susceptibility to SS has a strong association with certain HLA loci, particularly IRF5 and STAT4. Moreover, development of SS is reported in association with viral agents, particularly the Herpesviridae family [4,5], imbalances in the gastrointestinal microbiome, squaleneadjuvanted anti-H1N1 influenza vaccine [6], development of menopause [7], low vitamin D [8], stress [9], exposure to silica [10] and silicone [11].

SS targets exocrine glands throughout the body, primarily salivary and lacrimal apparatus, leading to severe dryness of eyes and mouth. Extra-glandular manifestations include fatigue, and arthralgias as well as impairments in skin, vascular and neurologic 
systems [12]. SS patients can develop various types of exocrine manifestations such as autoimmune thyroiditis, interstitial nephritis, or pneumonitis.

In a case that we described recently, a patient presented with markedly diminished axillary sweating. The biopsy demonstrated extensive fibrosis and a marked diminution in the number of eccrine structures, with glandular ectasia deep in the specimen. [13]

Although xerosis is an extremely common symptom in advanced SS, we know very little about the exact cutaneous processes in the affected skin, its chronology and its evolution in relation to salivary and lacrimal impairments. As with other autoimmune conditions, one might expect SS to cause systemic damage to all susceptible tissues. Although clinical manifestations begin due to salivary and lacrimal glands impairment, it is unknown if these glands are the initial targets of the disease or simply the most sensitive to the inflammatory damage. It is possible that cutaneous damage might happen concurrently with damage to other exocrine glands but not demonstrate clinical manifestations for a long time. There is no data in the literature nor any documented study of subclinical skin health in patients with already manifested SS. These patients may not yet exhibit cutaneous symptoms but steadily develop microscopic skin impairments. In order to investigate for the presence of a peri-eccrine, focally destructive autoimmune process involving eccrine structures, we conducted evaluation of 31 skin biopsies performed for other reasons on patients with diagnosed SS and asymptomatic skin.

\section{Materials and Methods}

The study protocol was approved by the Institutional Review Board at the University of Rochester School of Medicine and Dentistry. This study was based on the retrospective analysis of archival tissue. The study utilized surgical pathology specimens of patients who had been diagnosed with SS over the past 15 years (January 1st, 2004 to December 31, 2019). We found 162 such patients. From these 162 initial patients, 31 patients had skin biopsies for reasons not related to their SS diagnosis and were considered to be applicable to the study. Patients who were biopsied with an aim of diagnosing or staging of SS were excluded. All analyzed cases had primary pathology previously diagnosed by the dermatopathology unit in our institution and were reviewed for inclusion in this study by one of us (BRS).

The 31 skin biopsies contained a total of 84 eccrine structures and were reviewed in order to assess the number, distribution and pathologic changes within and around the eccrine ducts and glands. Eccrine structures were interpreted as separate clusters of eccrine ducts and glands. Acrosyringia were examined as part of the eccrine apparatus. Biopsies were analyzed for the extent, distribution and nature of any inflammatory infiltrate. We also observed for presence of any peri-eccrine fibrosis or other histologic changes that might hint at a prior inflammatory process.

Inflammation was scored from 0 to $4+$. A score of " 0 " was given when less than 5 inflammatory cells were found in close proximity to the eccrine structures $(<0.1 \mathrm{~mm})$, score " $1+$ " corresponded to 5 - 25 inflammatory cells, " $2+$ " similarly to 25 - 40 inflammatory cells, " $3+$ " to 40 - 50 inflammatory cells and " $4+$ " when more than 50 inflammatory cells were found in inflammatory infiltrate surrounding the sweat glands. We considered positive cases exhibiting " $1+$ " and higher degree of inflammation.

To evaluate the composition of inflammatory infiltrate, we stained all positive specimens with CD4, CD20 and CD 138. 
The control group included 31 random skin biopsies with no evidence of lupus erythematosus (LE), lichen striatus, Sjogren's syndrome or other diseases in which peri-eccrine infiltrate would be expected as a part of the disease process.

\section{Results}

Out of 84 eccrine structures $1+$ inflammation was noted in $25,2+$ in $19,3+$ in $2,4+$ in 4 and no inflammation appeared to be in 34 structures (see Table 1).

Table 1. Data from evaluation of eccrine structures according to study protocol (P - plasma cells, L - lymphocytes, EOS - eosinophils).

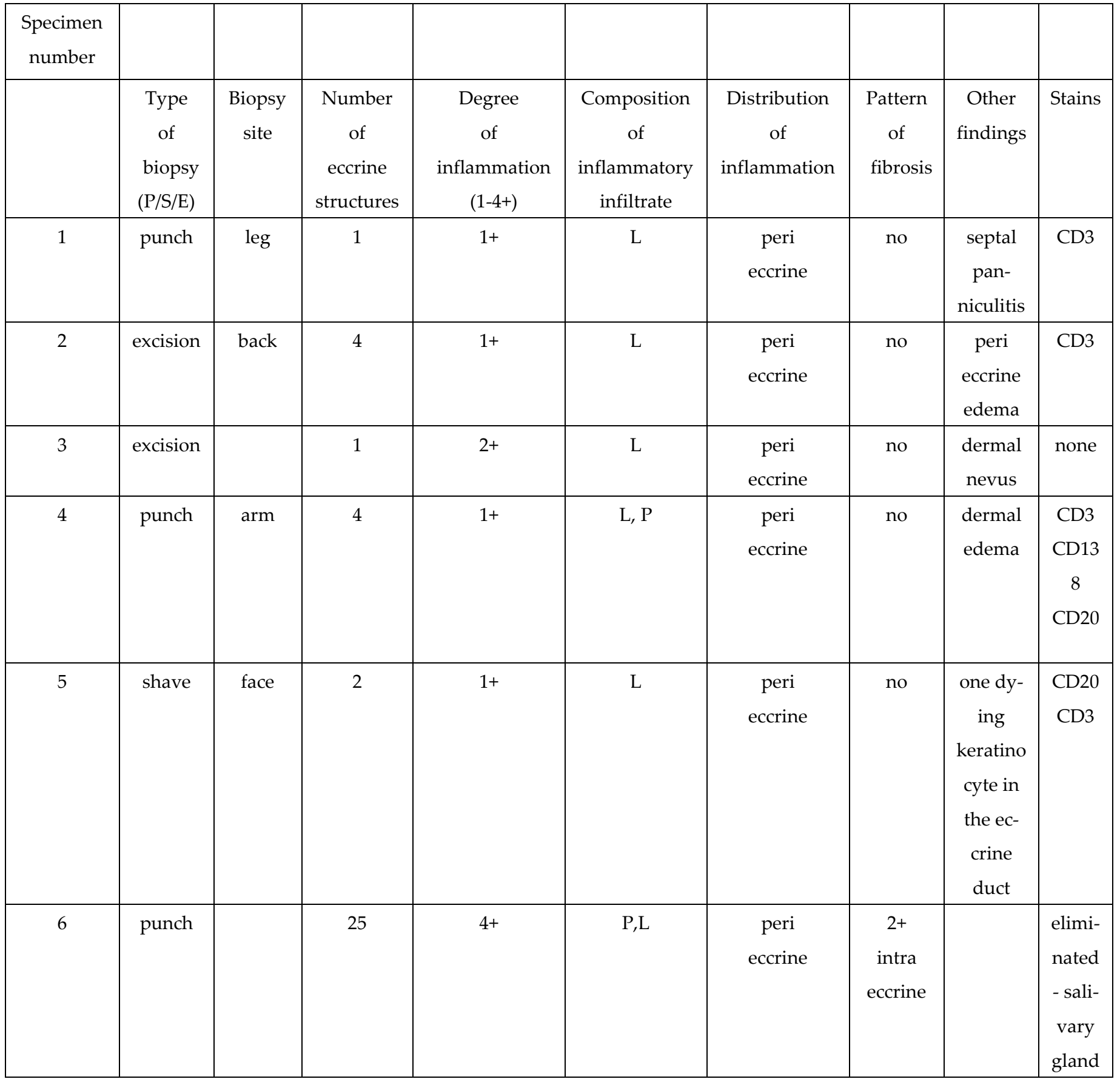




\begin{tabular}{|c|c|c|c|c|c|c|c|c|c|}
\hline 7 & punch & acral & 2 & $1+$ & $\mathrm{L}$ & $\begin{array}{c}\text { peri } \\
\text { eccrine }\end{array}$ & $\begin{array}{c}2+ \\
\text { intra } \\
\text { eccrine }\end{array}$ & & none \\
\hline 8 & excision & & 6 & $1+$ & $\mathrm{L}$ & $\begin{array}{c}\text { peri } \\
\text { eccrine }\end{array}$ & no & $\begin{array}{l}\text { more in- } \\
\text { flamma- } \\
\text { tion } \\
\text { around } \\
\text { ducts }\end{array}$ & none \\
\hline 9 & punch & & 2 & $2+$ & L, EOS & $\begin{array}{c}\text { peri } \\
\text { eccrine }\end{array}$ & no & & $\begin{array}{l}\text { CD3 } \\
\text { CD20 }\end{array}$ \\
\hline 10 & excision & & 5 & $\begin{array}{l}1+\text { in one } \\
\text { group only }\end{array}$ & $\mathrm{L}$ & $\begin{array}{c}\text { peri } \\
\text { eccrine }\end{array}$ & no & & CD3 \\
\hline 11 & excision & & 4 & 0 & & & & & \\
\hline 12 & excision & & 1 & 0 & & & & & \\
\hline 13 & excision & & 1 & $1+$ & $\mathrm{L}$ & $\begin{array}{c}\text { peri } \\
\text { eccrine }\end{array}$ & no & & CD3 \\
\hline 14 & punch & & 5 & $2+$ & $\mathrm{P}, \mathrm{L}, \mathrm{EOS}$ & $\begin{array}{c}\text { peri } \\
\text { eccrine }\end{array}$ & no & edema & $\begin{array}{c}\text { CD3 } \\
\text { CD13 } \\
8 \\
\text { CD20 }\end{array}$ \\
\hline 15 & punch & & 2 & $3+$ & L,EOS & $\begin{array}{c}\text { peri } \\
\text { eccrine }\end{array}$ & no & $\begin{array}{l}\text { hemor- } \\
\text { rhage } \\
\text { periec- } \\
\text { crine }\end{array}$ & $\begin{array}{l}\text { CD3 } \\
\text { CD20 }\end{array}$ \\
\hline 16 & shave & & 2 & $2+$ & $\mathrm{L}, \mathrm{P}$ & $\begin{array}{c}\text { peri } \\
\text { eccrine }\end{array}$ & no & & $\begin{array}{c}\text { CD13 } \\
8 \\
\text { CD20 } \\
\text { CD3 }\end{array}$ \\
\hline 17 & punch & & 2 & 0 & & & & no ducts & \\
\hline 18 & punch & & 1 & $1+$ & $\mathrm{L}$ & $\begin{array}{c}\text { peri } \\
\text { eccrine }\end{array}$ & no & & CD3 \\
\hline 19 & punch & & 2 & $2+$ & $\mathrm{L}, \mathrm{EOS}$ & $\begin{array}{c}\text { peri } \\
\text { eccrine }\end{array}$ & no & & $\begin{array}{l}\text { CD3 } \\
\text { CD20 } \\
\end{array}$ \\
\hline 20 & punch & & 5 & 0 & & & & & \\
\hline 21 & excision & & 2 & 0 & & & & $\begin{array}{c}\text { dying } \\
\text { keratino } \\
\text { cyte }\end{array}$ & \\
\hline 22 & punch & & 3 & $1+$ & $\mathrm{L}$ & $\begin{array}{c}\text { peri } \\
\text { eccrine }\end{array}$ & no & & CD3 \\
\hline 23 & shave & & 1 & 0 & & & & & \\
\hline
\end{tabular}




\begin{tabular}{|c|c|c|c|c|c|c|c|c|}
\hline 24 & shave & 1 & 0 & & & & & \\
\hline 25 & punch & 8 & $2+$ & L & $\begin{array}{c}\text { peri } \\
\text { eccrine }\end{array}$ & no & & $\begin{array}{l}\text { CD3 } \\
\text { CD20 }\end{array}$ \\
\hline 26 & punch & 4 & 0 & & & $\begin{array}{c}3+ \\
\text { peri and } \\
\text { intra } \\
\text { ductal }\end{array}$ & & \\
\hline 27 & punch & 1 & $1+$ & $\mathrm{L}$ & $\begin{array}{c}\text { peri } \\
\text { eccrine }\end{array}$ & no & & $\begin{array}{l}\text { CD3 } \\
\text { CD20 }\end{array}$ \\
\hline 28 & punch & 5 & $1+$ & $\mathrm{L}$ & $\begin{array}{c}\text { peri } \\
\text { eccrine }\end{array}$ & no & & CD3 \\
\hline 29 & shave & 1 & $1+$ & $\mathrm{L}$ & $\begin{array}{c}\text { peri } \\
\text { eccrine }\end{array}$ & no & & $\begin{array}{l}\text { CD3 } \\
\text { CD20 }\end{array}$ \\
\hline 30 & shave & 1 & $1+$ & $\mathrm{L}$ & $\begin{array}{c}\text { peri } \\
\text { eccrine }\end{array}$ & no & $\begin{array}{c}\text { dying } \\
\text { keratino } \\
\text { cyte }\end{array}$ & CD3 \\
\hline 31 & punch & 4 & $4+$ & L,P,Eos & $\begin{array}{c}\text { peri } \\
\text { eccrine }\end{array}$ & no & & $\begin{array}{l}\mathrm{CD} 3 \\
\mathrm{CD} 20\end{array}$ \\
\hline
\end{tabular}

The inflammatory infiltrate in all positive biopsies was peri-ductal without involvement of the eccrine glandular structures. In all cases, the peri-ductular inflammation was localized at some distance from the primary pathology for which the biopsy was performed and was judged to be an independent an unrelated process (see Figure 1).
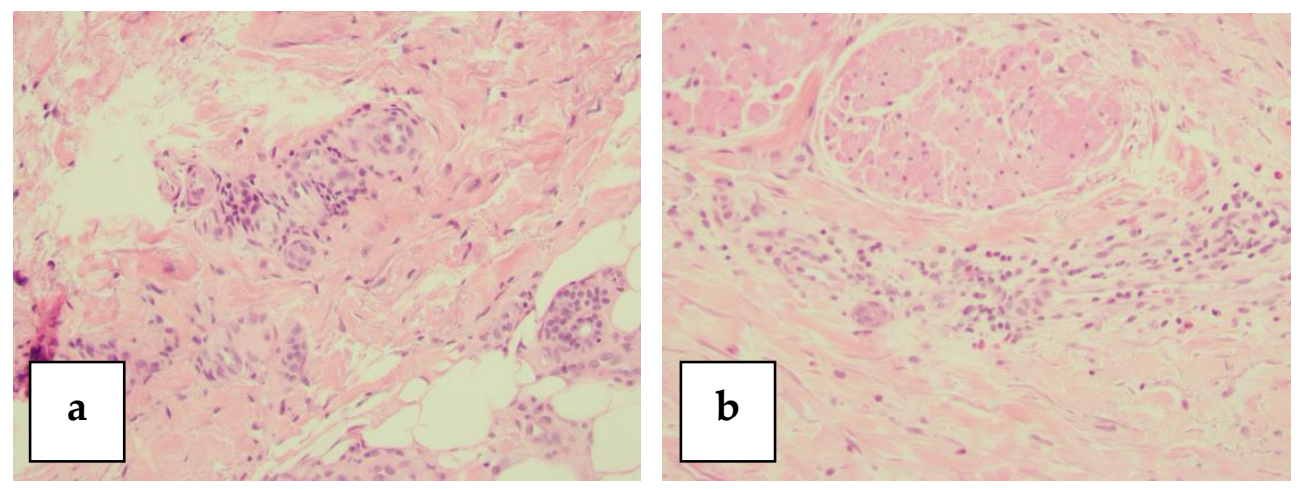

Figure 1.H\&Ex20. Histological findings in skin biopsies from SS patient without cutaneous symptoms. Figure "a" represents example of $1+$ peri-ductal inflammation, while figure " $\mathrm{b}$ " illustrates significantly higher number of inflammatory cells around the ducts and falls into category 4+ inflammation according to study protocol.

Immunohistochemical (IHC) stains revealed that the inflammatory infiltrates were purely composed of CD3+ T-cells in 14 structures, a mixture of CD3+ T-cells and CD20- B-cells in 24 structures, and a "cocktail" of inflammatory cells including CD3+ T-cells, CD20+ B-cells and CD138+ plasma cells was revealed in 12 structures (see Figure 2). 

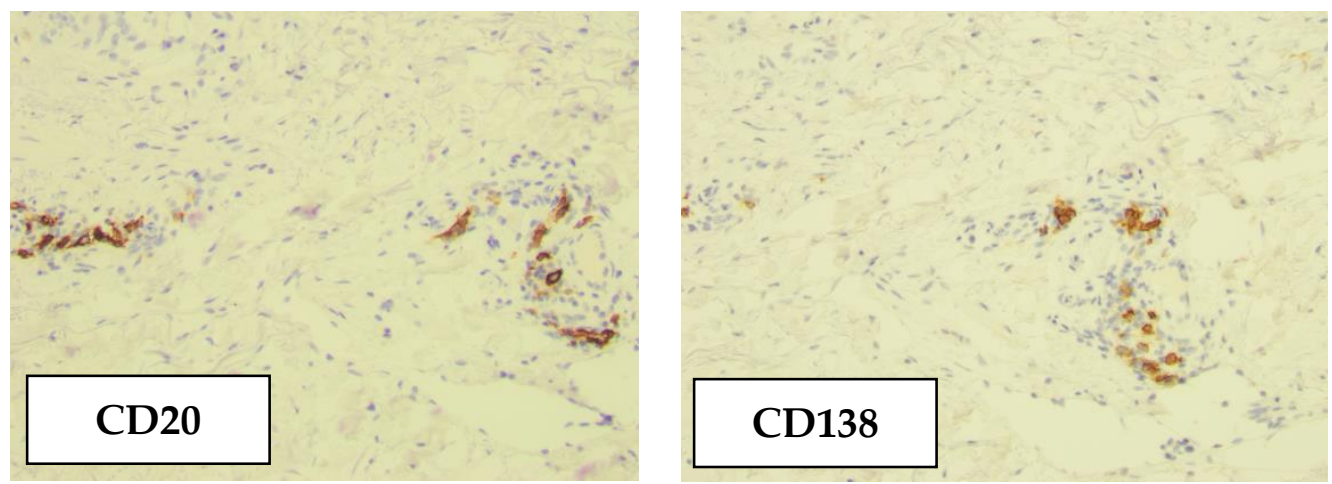

Figure 2.x200. Immunohistochemical analysis of peri - ductal inflammatory infiltrates. These figures represent example of $2+$ infiltrate with B-cells highlighted by CD20+ and 4+ infiltrate that was found to contain CD138+ plasma cells

We noted that cases with mild peri-ductal inflammation consistently demonstrated T-cells as the sole components of the process, while the presence of B-cells and plasma cells was noted with higher degrees of inflammation (see Figures $C \& D$ ).

Accompanied observations included peri-ductal eosinophils in 5 cases, peri-eccrine hemorrhage in 1 case and apoptotic keratinocytes in 2 eccrine ducts. Eosinophils were noted only in cases with higher degrees of inflammation and the presence of $B-$ lymphocytes and plasma cells.

Overall, $60 \%$ of biopsies demonstrated some degree of inflammation related to the eccrine ducts. In contrast, all 31 skin biopsies in the control group showed less than five lymphocytes around the eccrine structures and were scored as " 0 " according to the criteria listed above.

\section{Discussion}

Cutaneous manifestations of Sjogren's syndrome are broad [14],[15-17],[18],[19] with autoimmune anhidrosis/xerosis being described in $26-67 \%$ of patients $[15,20]$.

These symptoms are not routinely recognized or assessed for in SS patients and may be underestimated and commonly neglected $[18,21]$. To some measure, this is due to xerosis being perceived by clinicians as subjective and the fact that it is often associated with more attention demanding symptoms. This may also be attributed to a poor understanding of the mechanism of xerosis in SS patients. Herein, we demonstrated that most SS patients exhibit some degree of inflammation prior to developing any clinical cutaneous manifestations. These findings may play an important role in further understanding the pathophysiology of the disease in terms of its overall systemic nature, as well as the mechanism of disease progression, given the biological similarities between salivary and eccrine structures.

There are scattered publications describing the histology of xerotic skin in SS patients. Mitchell et al. described a skin biopsy in a patient with SS and hypohidrosis that showed a moderate number of eccrine glands and ductal structures in the reticular dermis and the presence of lymphocytes and plasma cells heavily infiltrating the epithelial structures [22]. Whaley et al. performed skin biopsies on seven patients with xerosis, showing a chronic inflammatory process destroying the sweat glands. A nonspecific perivascular lymphocytic infiltrate was found in this study [23]. In another study by Roguedas et al., axillary skin biopsies were performed on 12 of 22 patients previously diagnosed with SS to investigate the role of B and T-cells in the cutaneous pathogenesis of Sjogren's syndrome [24]. 
A lymphocytic infiltrate was identified in 8 cases (66\%). In addition to T lymphocytes, numerous B lymphocytes (marginal-zone-like and memory-type) were found within the inflammatory infiltrate surrounding eccrine ducts. Our findings correlate with data reported by the Roguedas' team, as well as these other studies. Additionally, we observed the composition of the inflammatory infiltrate to correlate with the degree of peri-eccrine inflammation. We demonstrated that $\mathrm{T}$ lymphocytes are the main components of the inflammatory infiltrate when inflammation is mild and the disease process is presumably in its initial stages, while increasing severity of inflammation is associated with presence of B-cells and plasma cells in the infiltrate. Therefore, it is possible to speculate that xerosis might result from immunologic destruction of the eccrine apparatus by an organized group of inflammatory cells with clearly defined roles for each member. It begins with $\mathrm{T}$ cells and leads to the production of antibodies by an erroneously selected and differentiated population of $B$ cells. This process would be analogous to the destruction of salivary or lachrymal glands [25]. Considering exclusively $\mathrm{T}$ - lymphotropic qualities of the epidermis, it would be very unusual to locate B- or plasma cells in the peri-eccrine zone in asymptomatic skin unless for a reason. Chemotactic factors for B-cells are described in labial salivary glands [26] and might similarly be produced by all exocrine tissue [27]. The location of the inflammatory infiltrate in our study suggests these chemotactic factors might be, in theory, secreted by ductular epithelium rather than gland itself. Further studies are necessary to test the validity of this speculation.

Our study is the first histologic evaluation of asymptomatic skin in SS patients. We demonstrated the majority of these patients to have mild inflammation in the peri-eccrine zone. In five cases with higher degree of inflammation (according to study protocol) we noted presence of eosinophils. Although not striking in samples from asymptomatic patients, these cells might have a meaningful role when inflammation gets serious. Eosinophils might influence secondary destruction of the ducts. They are recruited via $\mathrm{T}$ cells and IL-5 and might also regulate local tissue remodeling and fibrosis [28].

The diagnosis of SS is based on histopathological examination of the minor salivary glands. The diagnostic finding includes an inflammatory infiltrate surrounding salivary and lacrimal glands and ducts that is primary composed of lymphocytes and plasma cells (mostly in lacrimal glands). Additional features are parenchymal atrophy as well as fibrosis, ductal ectasia and acute inflammation. The most characteristic feature of SS on biopsy is focal lymphocytic sialadenitis, with a sensitivity and specificity of $>80 \%$ [29]. This is described as the presence of dense aggregates (foci) of $\geq 50$ mononuclear cells (mostly lymphocytes), in a peri-ductal or perivascular localization [30]. In our study, cases with 4+ inflammation ( 2 cases -29 structures) met this criterion demonstrating a huge discordance in disease manifestation between minor salivary gland findings and cutaneous eccrine glands. This may mean that minor salivary glands might be more sensitive to the chronic inflammatory damage than eccrine glands and possibly have weaker abilities to self-repair. An appropriate grading scale for peri-eccrine inflammation and its prognostic or diagnostic significance must be determined with a larger study and long-term patient follow-up.

Obtaining skin samples from patients with suspected or established SS might be helpful for disease staging as well as evaluation of therapeutic measurements [24, 31]. Since most of our cases revealed some degree of inflammation, we suggest that a majority of patients have subclinical cutaneous involvement at the time of the diagnosis. We support the idea to include skin biopsy in the routine care of SS. Evaluation of cutaneous exocrine glands might be particularly helpful in challenging situations i.e. symptomatic patients without identifiable sialadenitis etc. [32]. Skin biopsy could also serve as a secondary prognostic and diagnostic factor in those who simply decline lip biopsy because of cosmetic reasons. 
Early and a routine cutaneous evaluation in SS patients is a necessity due to therapy-induced immunosuppression and disease-associate immunodysregulation promoting skin malignancy. Also, patients with SS are known to have higher incidence of B-cell lymphomas compared to the general population or patients with other autoimmune diseases [34]. Skin lymphomas in patients with SS have been described and might be early detected on frequent skin checks in these patients. [35].

Author Contributions: Tatsiana Pukhalskaya, MD - Investigation, formal analysis, data curation, writing - original draft preparation. Bruce Smoller, MD - Conceptualization and methodology, formal analysis, resources, writing - review and editing.

Funding: This research received no external funding.

Institutional Review Board Statement: The study was conducted according to the guidelines of the Declaration of Helsinki and approved by the Institutional Review Board of URMC (STUDY00004274, approved 10/16/19). The study was reviewed and approved under the OHSP and UR policies, and in accordance with Federal regulation 45 CFR 46 under the University's Federalwide Assurance (FWA00009386).

Informed Consent Statement: Patients' consents ware waived since patients had already consented prior to the original biopsy. Only deidentified archival tissue material was utilized in this study.

Data Availability Statement: Data supporting reported results can be found on PubMed at https://pubmed.ncbi.nlm.nih.gov/

Acknowledgments: N/A

Conflicts of Interest: The authors declare no conflict of interest in this study.

\section{References}

1. 1. H. S. Zur Kenntnis der Keratoconjunctivitis sicca (Keratitis filiformis bei Hypofunktion der Tränendrüsen). Acta Ophthalmol (Copenh). 1933;11:1-151

2. 2. Kvarnstrom M, Ottosson $V$, Nordmark B, Wahren-Herlenius M. Incident cases of primary Sjogren's syndrome during a 5-year period in Stockholm County: a descriptive study of the patients and their characteristics. Scand J Rheumatol. 2015;44:13542. [PMID: 25222653].

3. 3. Bjork A, Mofors J, Wahren-Herlenius M. Environmental factors in the pathogenesis of primary Sjogren's syndrome. J Intern Med. 2020. [PMID: 32107824].

4. 4. Warvsten $\mathrm{A}$, Bjornfors $\mathrm{M}$, Arvidsson $\mathrm{M}$, et al. Islet autoantibodies present in association with Ljungan virus infection in bank voles (Myodes glareolus) in northern Sweden. J Med Virol. 2017;89:24-31. [PMID: 27283793].

5. 5. Nielsen PR, Kragstrup TW, Deleuran BW, Benros ME. Infections as risk factor for autoimmune diseases - A nationwide study. J Autoimmun. 2016;74:176-81. [PMID: 27267460].

6. 6. Brauner S, Folkersen L, Kvarnstrom M, et al. H1N1 vaccination in Sjogren's syndrome triggers polyclonal B cell activation and promotes autoantibody production. Ann Rheum Dis. 2017;76:1755-63. [PMID: 28760805].

7. 7. Mostafa S, Seamon V, Azzarolo AM. Influence of sex hormones and genetic predisposition in Sjogren's syndrome: a new clue to the immunopathogenesis of dry eye disease. Exp Eye Res. 2012;96:88-97. [PMID: 22227485].

8. 8. Ramagopalan SV, Goldacre R, Disanto G, et al. Hospital admissions for vitamin D related conditions and subsequent immune-mediated disease: record-linkage studies. BMC Med. 2013;11:171. [PMID: 23885887].

9. 9. Porcelli B, Pozza A, Bizzaro N, et al. Association between stressful life events and autoimmune diseases: A systematic review and meta-analysis of retrospective case-control studies. Autoimmun Rev. 2016;15:325-34. [PMID: 26708168].

10. 10. Sanchez-Roman J, Wichmann I, Salaberri J, et al. Multiple clinical and biological autoimmune manifestations in 50 workers after occupational exposure to silica. Ann Rheum Dis. 1993;52:534-8. [PMID: 8394065].

11. 11. Balk EM, Earley A, Avendano EA, Raman G. Long-Term Health Outcomes in Women With Silicone Gel Breast Implants: A Systematic Review. Ann Intern Med. 2016;164:164-75. [PMID: 26550776].

12. 12. Bartoloni E, Alunno A, Gerli R. The dark side of Sjogren's syndrome: the possible pathogenic role of infections. Curr Opin Rheumatol. 2019;31:505-11. [PMID: 31135384].

13. 13. Gadarowski MB. Acquired Anhidrosis In A Patient With Sjogren's Syndrome and Silicone Breast Implants. JAAD Case Reports.

14. 14. van Nimwegen JF, van der Tuuk K, Liefers SC, et al. Vaginal dryness in primary Sjogren's syndrome: a histopathological case-control study. Rheumatology (Oxford). 2020. [PMID: 32044981].

15. 15. Bernacchi E, Amato L, Parodi A, et al. Sjogren's syndrome: a retrospective review of the cutaneous features of 93 patients by the Italian Group of Immunodermatology. Clin Exp Rheumatol. 2004;22:55-62. [PMID: 15005005]. 
16. 16. Roguedas AM, Youinou P, Lemasson G, et al. Primary Gougerot-Sjogren syndrome: a dermatological approach. J Eur Acad Dermatol Venereol. 2006;20:243-7. [PMID: 16503880].

17. 17. Hsu HC, Lin CY, Shih IH, Shen SC. Lymphocytic hidradenitis: A distinctive histopathological finding of annular erythema of Sjogren syndrome. Australas J Dermatol. 2018;59:e198-e202. [PMID: 28771678].

18. 18. Katayama I. Dry skin manifestations in Sjogren syndrome and atopic dermatitis related to aberrant sudomotor function in inflammatory allergic skin diseases. Allergol Int. 2018;67:448-54. [PMID: 30104151].

19. 19. Albrecht J, Atzeni F, Baldini C, et al. Skin involvement and outcome measures in systemic autoimmune diseases. Clin Exp Rheumatol. 2006;24:S52-9. [PMID: 16466625].

20. 20. Bloch KJ, Buchanan WW, Wohl MJ, Bunim JJ. Sjoegren's Syndrome. A Clinical, Pathological, and Serological Study of Sixty-Two Cases. Medicine (Baltimore). 1965;44:187-231. [PMID: 14315274].

21. 21. Katayama I, Yokozeki H, Nishioka K. Impaired sweating as an exocrine manifestation in Sjogren's syndrome. Br J Dermatol. 1995;133:716-20. [PMID: 8555022].

22. 22. Mitchell J, Greenspan J, Daniels T, et al. Anhidrosis (hypohidrosis) in Sjogren's syndrome. J Am Acad Dermatol. 1987;16:233-5. [PMID: 3819059].

23. 23. Whaley K, Williamson J, Chisholm DM, et al. Sjogren's syndrome. I. Sicca components. Q J Med. 1973;42:279-304. [PMID: 4785436].

24. 24. Roguedas AM, Pers JO, Lemasson G, et al. Memory B-cell aggregates in skin biopsy are diagnostic for primary Sjogren's syndrome. J Autoimmun. 2010;35:241-7. [PMID: 20655174].

25. 25. Maeda A, Yamanouchi H, Lee JB, Katayama I. Oral prednisolone improved acetylcholine-induced sweating in Sjogren's syndrome-related anhidrosis. Clin Rheumatol. 2000;19:396-7. [PMID: 11055832].

26. 26. Hansen A, Odendahl M, Reiter K, et al. Diminished peripheral blood memory B cells and accumulation of memory B cells in the salivary glands of patients with Sjogren's syndrome. Arthritis Rheum. 2002;46:2160-71. [PMID: 12209521].

27. 27. Binard A, Le Pottier L, Devauchelle-Pensec V, et al. Is the blood B-cell subset profile diagnostic for Sjogren syndrome? Ann Rheum Dis. 2009;68:1447-52. [PMID: 18782791].

28. 28. Aceves SS. Remodeling and fibrosis in chronic eosinophil inflammation. Dig Dis. 2014;32:15-21. [PMID: 24603375].

29. 29. Vitali C, Moutsopoulos HM, Bombardieri S. The European Community Study Group on diagnostic criteria for Sjogren's syndrome. Sensitivity and specificity of tests for ocular and oral involvement in Sjogren's syndrome. Ann Rheum Dis. 1994;53:637-47. [PMID: 7979575].

30. 30. Chisholm DM, Mason DK. Labial salivary gland biopsy in Sjogren's disease. J Clin Pathol. 1968;21:656-60. [PMID: 5697370].

31. 31. Tobón GJ. Skin biopsy as a routine diagnostic tool for primary Sjogren's syndrome. Int J Clin Rheumatol. 2011;6:291-6

32. 32. Radfar L, Kleiner DE, Fox PC, Pillemer SR. Prevalence and clinical significance of lymphocytic foci in minor salivary glands of healthy volunteers. Arthritis Rheum. 2002;47:520-4. [PMID: 12382301].

33. 33. Dauphinee M, Tovar Z, Talal N. B cells expressing CD5 are increased in Sjogren's syndrome. Arthritis Rheum. 1988;31:642-7. [PMID: 3259883].

34. 34. Abrol E, Gonzalez-Pulido C, Praena-Fernandez JM, Isenberg DA. A retrospective study of long-term outcomes in 152 patients with primary Sjogren's syndrome: 25-year experience. Clin Med (Lond). 2014;14:157-64. [PMID: 24715127].

35. 35. Royer B, Cazals-Hatem D, Sibilia J, et al. Lymphomas in patients with Sjogren's syndrome are marginal zone B-cell neoplasms, arise in diverse extranodal and nodal sites, and are not associated with viruses. Blood. 1997;90:766-75. [PMID: 9226177]. 